\title{
Modeling expectations of resort-tourist market of Ukraine
}

\author{
Pavel Zakharchenko, ${ }^{1,}$, Anna Kostenko ${ }^{1}$, Tatyana Kungurtseva-Mashchenko ${ }^{1}$, and Illona Gorbachova ${ }^{1}$ \\ ${ }^{1}$ Berdyansk State Pedagogical University, Department of Economics, Entrepreneurship and Finance, 4, Schmidta str., Berdyansk, \\ 71100, Ukraine
}

\begin{abstract}
In modern world economy resort recreations is one of the most high-profitable spheres of managing. Ukraine owns the powerful resort and tourist potential, to which effective development can bring a real economic benefit. For this purpose, it is necessary to form of system concept for the development of such systems, which are integral part of the economic transformations. Transformational processes are displayed in shifts in consumption, requirements and ways of their satisfaction. The market environment needs are in the form of demand and ways to meet them mediated by the market in the form of market expectations. They are important for forecasting the behavior of the market of resort and tourist products. As a result, of research was the model of dynamics of trust of the market to transformational changes of the resort and tourist sphere of Ukraine is constructed. Scenarios of change of level of trust at various values of parameters, which correspond to stages of development of transformational economy are received.
\end{abstract}

\section{Introduction}

In the modern world economy resort-recreation and tourism activity is one of highly profitable spheres, as well as one of the most dynamically developing. For many countries this is not only constantly growing a source of financial revenues, but also due to attraction of millions of tourists as a source of infrastructure development for the territories, creating additional jobs.

Ukraine has a powerful resort-recreation and tourist potential, the effective use of which can ensure not only full satisfaction of the needs of the population in such services, but also bring real economic benefits. Therefore resort-recreation and tourism spheres in the process of market transformation of the economy should take one of the leading places in the structure of the economic complex. Such a perspective for national resort and tourist complexes is intended to provide appropriate methodologies for systemic economic transformations, based on modern concepts of research of complex economic systems and, first of all, by methods of system research and economic-mathematical modeling.

The problem of the transformation of economic systems has deep grounds in the problem of general economic theory. The problems of the formation, development, and change of economic systems, which were investigated in the works of many scientists throughout the long period of time, are directly related to it. In the process of the research of economic transformation of resort and tourist systems the authors relied on the theoretical developments which are contained in works of M. Bokov [1], M. Amirkhanov [2], A. William [3], E. Inskeep [4], A. Shekhovtseva [5] and other scientists [6-8].
Researches of accounting for expectations in the economic systems is presented in the writings of J. Keynes [9] and J. Hicks [10], who emphasized that expectations are part of the system, while fulfilling the role of the exogenous factor, but not the element which is formed in the analyzed process.

Historically the first researcher who formulated the hypotheses underlying the theory of rational expectations was J. Muth [11]. His idea was picked up and applied to a large range of economic models by R. Lucas. [12] As a result of it, the principle of rational expectations has been recognized as the theoretical basis for new research, including surveys of the resort and tourist economics.

\section{Methodological aspect of a research of expectations of the resort-tourist market}

Economic transformations of the resort and tourist economy represent large-scale and deep transformations of a system character. They have their own regularities, the detection of which allows not only to estimate their current state, but also to forecast trends in development. Transformation processes are reflected in shifts in consumption, needs and ways to meet them. In a market environment the needs are in the form of demand, and the ways of their satisfaction are mediated by the market in the form of market expectations.

The concept of "market expectation"” was formed on the basis of provisions of probability theory and psychology. It is important for forecasting market behavior, and, consequently, the functioning of the transformational economy. As G. Hodgson [13] noted, the effectiveness of influence of expectations in transformational economies is not lower than in the 
developed and stable economies. Thus, there is a need of justification of content of expectations, explanations their role as ekzo- and endogenous factors of the economic system and development of the corresponding models of forecasting, in particular for the market of resort and tourist products. Expectations of economic entities are usually not studied as separate objects of analysis, but they are investigated in the form of "embedding" expectations in the transformational functioning of economic systems.

In the modern economic theory [14] allocate two types of expectations: "ex post" and "ex ante". Expectation of "ex post" is the assessment given by the subjects of the economy after the completion of the considered process. They are accounted for mainly in empirical verification of theoretical concepts or in calculating the actual indicators of economic development based on the system of national account. Expectation of "ex ante" is future plans and intentions of economic subjects, which define the nature of the decisions which they make. The formation of economic subjects of rational expectations, "ex ante" is of direct interest to the analysis of the transformational processes in the resort-tourism economy as a mechanism for market self-regulation.

The theory of expectations allocates three types of expectations of "ex ante": static, adaptive, rational.

Static expectations assume that in the future economic subjects are guided by the same parameters of an environment, which take place today. That is the simplest rule in decision-making for economic subjects will work this year as and in previous.

According to the theory of adaptive expectations, economic subjects build the behavior on the basis of past experience, but adjust the expectations, first, taking into account wrong estimates of the past, secondly, taking into account obvious changes of an economic environment.

Rational expectations provide that economic subjects form the plans and build the behavior, proceeding from the analysis of all of information available at the moment. Rationally acting economic subjects not only consider experience past mistakes, but also look in the future. Making the decision, they rely on own representations concerning model of management of economy and attract all available information on the expected events which can affect an economic environment. As a result it turns out that subjects, forming the forecasts, do it in the same way, as well as the market, that is, without allowing systematic mistakes.

One of the most important problems of the transformational economy is the level of confidence in transformational changes by economic agents, since, in case of its absence or low level, they can not achieve their goals [15]. According to the ideas of a number of researchers [16], the market system works to a large extent thanks to trust. In the act of trust, the complexity of the future is minimized. Trusting, the agent acts as if the future provides only strictly certain variants of the development of events. Rational trust: people use their available information to make the forecast, and then on its basis to make a decision. As the analysis of past experience provides risk assessment, formation of expectations generation and focus on future results, allocatet strategic or based on knowledge trust (strategic or knowledgebased trust) [17]. In this case the decision on trust is taken in the same way as the investment scheme: the efficiency of the decision on trust is determined in the long term by the results of the implementation of economic transformations.

The institute of trust helps subjects of the market to determine institutionally market space that in turn reduces uncertainty level. The level of credibility depends on such circumstances as:

- accounting of economic transformations by economic agents of past experience in sectors of economy;

- stability of national economy;

- international experience of development of economic systems, including, systems of a certain orientation [18].

At the same time it should be noted that the inefficiency of transformational strategy is connected not with a set of these or those tools, and it is caused by reaction of economic agents to the expected results from these economic transformations. Thus, the trust can be considered as one of the built-in regulating mechanisms of the market and economy in general. It is one of the most important determinants of distribution of investments and consumer demand.

In the relation to the market of resort-recreation products, we will consider a hypothesis of imperfection of information, which consists in recognition of differences in knowledge of agents of price dynamics depending on degree consumption of the corresponding resort products by them. It is supposed that agents are better informed on the prices on resort-recreation products, which they make and sell, than about the prices of other products which they buy. Let's show it on the basis of use "island" models.

The market of each individual resort-recreation product is similar to the island. Each agent, like an islander, does not have complete information about what is happening on other islands (or markets). Therefore, when there is an increase in prices for a resort-recreation product, he does not know exactly the reason for it.

He does not know if there is an increase in prices as a result of increased demand or an increase in the amount of money in circulation. Agents and firms operating in accordance with the concept of rational expectations regard the increase in prices for the resort-recreation market partly as a consequence of overall price increases, and partly as a result of the change in the relative price of the resort-recreation product due to its innovation.

Respectively, even if advance in price of a product it is quite caused by the general rise in prices, then rationally conceiving agent all the same assumes that the relative price of a resort product also grew by a certain size. As a result it expands production, other islanders agents join it, and in resort-recreation economy rise is observed.

Thus, application of the theory of rational expectations provides attraction of the mechanism of market self-regulation of economy in resort-recreation economy. During the competition all levers of self- 
regulation are put in action, it is effective self-regulation a resort-recreation system and providing its balance.

Rational expectations promote clearing of the market of resort-recreation products, its reduction to a state when stability of recreational economy as economic agents can react more flexibly to any deviations of an economic environment is provided, work according to the principles of optimization, being guided by real economic indicators and results.

\section{Model expectations of resort-tourist market}

An important role in the dynamics of confidence level is played by both the process of natural self-development of trust and the crisis of confidence. Natural selfdevelopment of trust arises in the case when the party fulfills its obligations, confidence in it increases; as a consequence, either the demand for the product increases or investment increases. Confidence crisis means a situation in which a party fails to fulfill its obligations; as a result, the trust in it falls sharply [19]. For the analysis of these processes, we will construct model of the dynamics of trust in the resort and tourist market by transformational changes of the resort and tourism sphere of activity.

Let $X$ be the amount of free capital that can be provided to companies resort and tourism spherec. According to the principle of natural increase of trust, while companies carry out transformation changes in order to produce an innovative resort and tourist product, trust in them is growing. Let $Y$ be the amount of funds for those companies that do not transform changes. Let's describe the dynamics of the change of these variables with the help of the following model

$$
\begin{aligned}
& \frac{d X}{d t}=\alpha_{1} X-\alpha_{2} X Y \\
& \frac{d Y}{d t}=-\beta_{1} Y+\beta_{2} X Y
\end{aligned}
$$

The parameter $\alpha_{1}$ reflects the growth rate to the companies in the tourist and tourist spherec depending on already carried out economic transformations. The value of the parameter $\alpha_{1}$ depends on the psychological factors. In particular, the index can be used to determine this parameter: investor confidence indices, consumer confidence indices, consumer expectations indices, consumer confidence indices, etc. In essence, this parameter reflects the trust of a large number of investors. Obviously, the parameter $\alpha_{1}$ tends to increase in the case of the effectiveness of transformational changes and to decrease in the absence of them.

The parameter $\alpha_{2}$ reflects the intensity of loan of means by inefficient companies, that is such which do not make transformational changes. Gain of loans proportional as quantity $Y$, since, the larger the resort company, the more it needs the funds to function, and the quantity $X$ - since, the more free capital in the market, the greater the potential for growth of companies that carry out economic transformations.
The parameter $\beta_{1}$ reflects the speed of insolvency of inefficient resort and tourism companies without external financing. As a parameter estimate, you can use the ratio of the following form: "(company's annual expenses annual revenue) / (company's assets)". For small and medium resort and tourism businesses it makes sense to consider the parameter $\beta_{1}$ close to zero or even in the area of small negative values. The considerable share of growth in small and medium businesses is possible, precisely because it is initially a great deal of trust in it, and it grows on this trust until it becomes ineffective.

The parameter $\beta_{2}$ reflects the speed of growth in the volume of inefficient resort-tourism companies by attracting investment. The increase is proportional as quantity $Y$, since, the larger the resort company, the more money it can use to grow, and - because $X$, the more capital on the market, the easier it is to get investment funds.

\section{Simulation results}

For computer simulation used software package MathCad. Let's consider different scenarios, obtained as a result of modeling of dynamics of the level of trust at different values of parameters.

Scenario I. Incomplete or ineffective economic transformations in resort and tourist companies.

One scenario obtained when modeling the level of market confidence was a scenario, corresponding to the situation of incomplete or ineffective economic transformations in resort and recreation companies (Fig. 1).

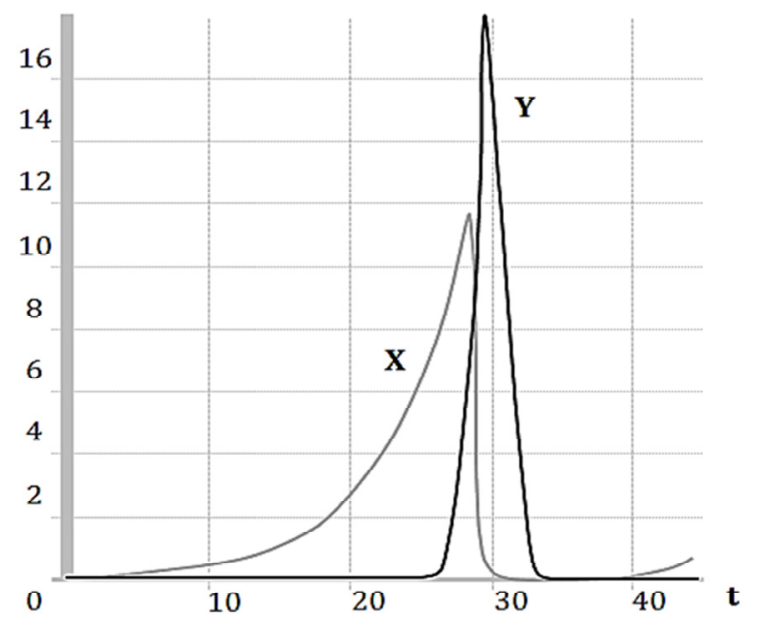

Fig. 1. Results of simulation of the dynamics of trust at $\alpha_{1}=0.2, \beta_{1}=0.8, \alpha_{2}=0.2, \beta_{1}=0.4$.

As can be seen from Fig. 1, the transformational changes lead to growth of trust of the market, which, accordingly, involves the flow of free capital into the resort and tourist market. Thus, an increase in the parameter $X$ means the period of market growth. To a certain amount of free capital the market is successfully developing, which makes it possible to talk about the transformational rate of growth of resort tourism companies. At some stage (moment of time $t=28$ ), 
between peak $X$ and crossing that goes up $Y$ the inefficient companies begin to be formed.

Starting from this moment, the trust of the market falls, and the amount of free capital is decreasing. However, due to the inertia of the economy, this fact is not fixed by indicators, since a significant amount of capital is invested in resort and tourist companies, and in general the capitalization of the resort and tourism sphere grows (growth of value $Y$ ). Then comes the situation when the volume of the capital of inefficient companies reaches its peak (peak $Y$ ). This happens in the absence of new investments in these companies due to lack of trust. Due to the high importance of inefficiency $\left(\beta_{1}=0.8\right)$, resort-tourism companies are rapidly losing profit and are forced to undergo economic transformation. Thus, a new transformation cycle begins.

Scenario II. The growth of completed economic transformations in resort and tourist companies.

Another scenario obtained when modeling trust of the market was a scenario, corresponding to the situation of the growth of the number of completed economic transformations in resort and tourist companies (Fig. 2).

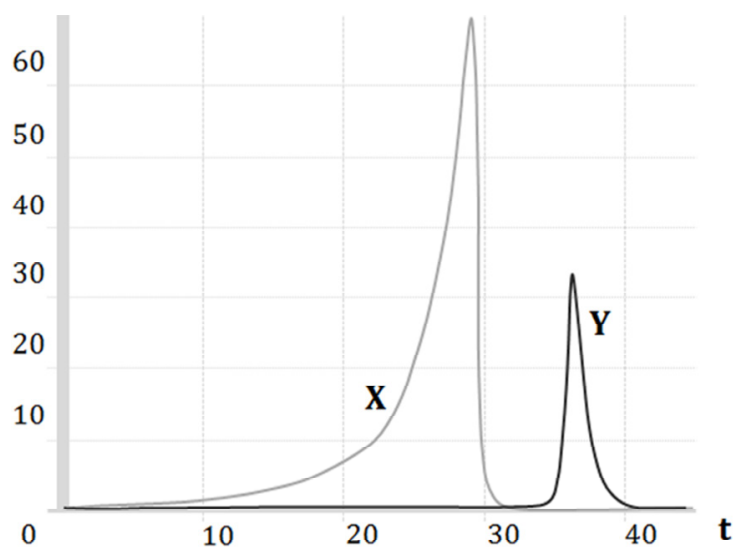

Fig. 2. Results of modeling of dynamics of trust at $\alpha_{1}=0.2, \beta_{1}=0.8, \alpha_{2}=0.2, \beta_{1}=0.2$.

The scenario is presented on Fig. 2 constructed on a basis the assumption that the volume of investment into ineffective resort-tourism companies will decrease in connection with reduction of trust of the market $\left(\beta_{1}=0.1\right)$.

The completion of economic transformations in resort and tourist companies leads to growth of trust of the market and, consequently, an increase in free capital in this market. If, for whatever reason, economic transformations do not fully achieve their goals, then the market is seen as an ineffectiveness of their work. At the same time, the level of trust does not decrease.

Scenario III. Regulations of the market in the conditions of transformational economy.

The scenario presented in Fig. 3 shows a high level of market confidence, which, accordingly, leads to a much larger accumulation of free capital (compared to scenario 1). For modeling of such scenario of trust resort and tourist the market we will reduce some parameters of model. On Fig. 3 the scenario of the regulated market in the conditions of transformational economy is shown.



Fig. 3. Results of modeling of dynamics of trust at $\alpha_{1}=0.2, \beta_{1}=0.1, \alpha_{2}=0.05, \beta_{1}=0.05$.

In the conditions of transformational economy, market regulators seek not to allow a market collapse. It is reached in the different ways, but with one purpose: to prevent the emergence of obviously inefficient resorttourism companies by reducing the opportunities for attracting investment in such companies. For modeling of such scenario of trust in the resort-tourism market we will reduce some parameters of the model. In Fig. 3 shows the scenario of a regulated market in a transformational economy $\left(\alpha_{2}=0.05, \beta_{1}=0.1, \beta_{2}=0.05\right)$.

It should be noted that in case of application to inefficient resort travel agencies decrease in trust, an opportunity to distance the beginning of the following transformational cycle exists the regulator of the market of the corresponding procedures.

The scenario is presented in Fig. 3 shows a high level of market confidence, which, accordingly, leads to a much larger accumulation of free capital (compared to scenario I). However, in this case, starting with a certain amount of free capital (the moment of time $t=30$ ), there is the emergence and development of inefficient resort and tourism companies. The emergence of such companies is mainly due to the incompleteness of economic transformations or the failure to achieve the objectives of transformational changes. It should be noted that if applied to ineffective resort and tourism companies regulating the market for appropriate procedures for reducing confidence, there is the possibility of delaying the start of the next transformation cycle.

Scenario $I V$. Weakly regulated or innovative market.

To one more scenario received when modeling trust of the market was the scenario corresponding to the situation of completing economic transformations in resort and tourist companies and transition to release of innovative resort and tourist products (Fig. 4).

The indicated scenario reflects the level of trust of the weakly regulated or innovative market. This market is characterized by a high intensity of loan of means by the inefficient companies $\left(\alpha_{2}=0.8\right)$, growth of volume of their means by attraction of investmentsan $\left(\beta_{2}=0.8\right)$, a large inefficiency of inefficiency $\left(\beta_{1}=0.5\right)$, which constantly enters new investors $\left(\alpha_{1}=0.5\right)$. The analysis of the scenario demonstrates the frequent change in market 
advantages at the expense of the high "growth rate of trust", as well as the fact that the amplitude of the cyclical changes for $X$ and $Y$ is low. Consequently, the level of market trust is distributed between transformational and inefficient resort and tourism companies and there is no accumulation of free capital in certain companies.



Fig. 4. Results of modeling of dynamics of trust at $\alpha_{1}=0.5, \beta_{1}=0.5, \alpha_{2}=0.8, \beta_{1}=0.8$.

\section{Conclusions}

The complex analysis of the role and place of resortrecreations in the development of the national economy and trends in changing their state in the process of European integration of the Ukrainian economy has been carried out. It has been shown that, as in many developed countries, this activity can be one of the most profitable and most dynamically developed spheres of the national economy. It also to be among the primary budget forming branches in case of transformation of management of economic processes on the basis of modern European paradigms and modern tools of their analysis.

An analysis of the current state and trends in the development of the world and domestic resort-recreation sphere has made it possible to conclude that the management of the economic development of the resortrecreation sphere in the present conditions should be based on the consideration of the nonlinear, stochastic nature of the flow of economic processes, both external and internal environment, inherent in the European. It is advisable to research these processes on the basis of innovation activity. It allows researching the development of complex socio-economic systems in the conditions of high degree of uncertainty of the external environment; systems of universal, general theoretical, specific principles and a set of basic concepts.

Thus, the analysis of the results of the modeling of the dynamics of confidence at different values of the parameters allows us to conclude that the level of trust in transformational changes by economic agents is one of the most important parameters for forecasting the behavior of the market, and, consequently, the functioning of the transformational economy as a whole. Market expectations in the course of the transformation cycle should be in line with the second scenario of the model, that is, the growth of completed economic transformations in resort and tourist companies. In this case, there is a significant increase in free capital in this market, which leads to an increase in demand for resort and recreational products.

\section{References}

1. Bokov, M.: Strategic management of recreational enterprises in conditions of transitional economy. National Institute for Strategic Studies, Kyiv (2011)

2. Amirkhanov, M., Tatarinov, A.: Economic problems of development of recreation regions. Helios, Kyiv (2017)

3. William, A.: Recreation and the Local Economy an Input-Output Model of a Recreation-Oriented Economy. Graduate School of Business University of Wisconsin-Madison (2012)

4. Inskeep, E.: National and Regional Tourism Planning: Methodologies and Case Studies. Polect, New York (2014)

5. Shekhovtseva, A.: Competitiveness of the region: the factors and method of creating. Marketing in Russia and abroad. 4, 11-15 (2010)

6. Galasyuk, S.: Analysis of level of competitiveness of regional market of tourist services. Bull. Khmel'nitsk National University. 2, 89-93 (2010)

7. Malinetskii, G.: Mathematical Foundations of Synergetics: Chaos, structures, computational experiment. URSS, Moscow (2015)

8. Mikulsky, K.: Problem of transformation and transition to a regular market economy. Economic, Moskow (2012)

9. Keynes, D.M.: The General Theory of Employment, Interest and Money. Palgrave Macmillan, London (2007)

10. Hicks, J.: Automatists, Hawtreyans and Keynesians. Journal of Money Credit and Banking. 2, 311-323 (2009)

11. Muth, J.: Rational Expectations and the Theory of Price Movements. Journal of Econometric. 29, 315-335 (2011)

12. Lucas, R., Sargent, J.: Rational Expectations and Econometric Practice. Allen \& Unwind, London (2011)

13. Hodgson, G.M.: Economics and Institutions: A Manifesto for a Modern Institutional Economics. Polite Press, Cambridge (1988)

14. Dovbenko, M., Osyk, Yu.: Modern economic theories in the works of Nobelians. National Institute for Strategic Studies, Kyiv (2011)

15. Seligman, A.B.: The Problem of the Trust. Princeton University Press, Princeton (2000) 
16. Stiglitz, J.E.: The Roaring Nineties: Seeds of Destruction. Allen Lane, London (2013)

17. Sangnier, M.: Does trust favor macroeconomic stability. Journal of Comparative Economic. 41(3), 653-668 (2013)

18. Nunkoo, R., Ramkissoon, H., Gursoy, D.: Public trust in tourism institutions. Journal of Annals of Tourism Research. 39(3), 1542-1544 (2012)

19. Khoskynh, D.: Economy of trust. Nedotorkannyj zapas. 5, 21-29 (2017) 